\title{
Recurring Anaphylaxis: A New Line of Questioning for your HPI
}

\author{
Lana Wahid $^{1 *}$, Sameh Aziz ${ }^{2}$ and Christina Abraham ${ }^{3}$ \\ ${ }^{1}$ Department of Internal Medicine, Virginia Tech Carilion School of Medicine, USA \\ ${ }^{2}$ Department of Pulmonary, Critical Care and Sleep Medicine, Virginia Tech Carilion School of Medicine, USA \\ ${ }^{3}$ Allergy and Asthma Associates, Roanoke Virginia, USA
}

*Correspondence: Lana Wahid, Internal Medicine Residency, Carilion Clinic-Virginia Tech, Carilion School of Medicine, USA, Tel: 5409817000; E-mail: 1wahid@carilionclinic.org

\begin{abstract}
Anaphylaxis is a serious life-threatening allergic reaction that typically has an immediate onset. It can present as flushing, angioedema, shortness of breath, rash and result in death if not treated immediately. In the past ten years, an emerging cause of delayed anaphylaxis has been identified. An IgE antibody to a mammalian oligosaccharide epitope (alpha-gal, or galactose-alpha-1,3-galactose) has been linked to both immediate and delayed onset anaphylaxis. The immediate form is associated with the first exposure to cetuximab; whereas the delayed onset occurs after ingestion of mammalian meat such as beef and pork. The presentation can develop 2-6 hours after ingestion. This IgE antibody to alpha-gal is strongly suggested that Lone Star tick bites have been the culprit. It is imperative when caring for an anaphylaxis patient of unknown etiology, to consider a line of questioning to not only include recent tick bites, but also last 2-3 meals ingested to identify if mammalian meat may have been the trigger.

Keywords: Delayed anaphylaxis; Anaphylactic shock; Alpha-gal; Red meat; Food allergy; Tick bites; Lone Star tick; Red meat; Beef; Pork; IgE antibody
\end{abstract}

Received Date: June 15, 2019; Accepted Date: July 05, 2019; Published Date: July 10, 2019

\section{Background}

Anaphylactic shock is a potentially life-threatening condition. Annual emergency department visits for anaphylaxis in the United States is estimated at over 500,000. It's prevalence in the general population is approximately $1.6 \%$ and has been reported as high as $5.1 \%$ with food triggers causing approximately $31 \%$ of the cases. The one food culprit that has recently come to light are those with specific carbohydrate moieties such as galactose- $\alpha-1,3$ galactose (alphagal). Alpha-gal is known to be present on non-primate mammalian tissues and meat and is known to elicit serious and fatal reactions. We present a case of recurring delayed anaphylaxis in an avid outdoorsman [1].

Citation: Lana Wahid, Recurring Anaphylaxis: A New Line of Questioning for your HPI. J Clin Cases Rep 3(1): 18-21. 


\section{Case Report}

A 60-year-old man with a past medical history to include hypertension, hyperlipidemia and arthritis with left hip replacement was in his usual routine at work when he developed sudden onset pruritus to his ears and scrotum followed by swelling to his throat and face. His voice was muffled as he arrived to an urgent care clinic where he was treated with intravenous methylprednisolone, subcutaneous epinephrine, and diphenhydramine for anaphylaxis. There was immediate improvement with his throat swelling. He was then transferred to the emergency department for persistent hypoxia as he continued to require supplemental oxygen [2]. When he arrived to the emergency department, his throat swelling and dyspnea returned. He required a second dose of epinephrine subcutaneously, intravenous diphenhydramine, followed by ranitidine and was then admitted to the intensive care unit (ICU) for anaphylactic shock. After admission, it was discovered he had stopped at his favourite fast food restaurant for a double cheeseburger approximately three hours before his symptoms began. He had previously seen an Allergist from six years of age until he was 40 for monthly “allergy shots" for hay fever [3].

\begin{tabular}{|c|c|c|}
\hline Component Results & Value & $\begin{array}{c}\text { Reference Range } \\
\text { \& Units }\end{array}$ \\
\hline $\begin{array}{l}\text { Galactose-Alpha-1,3Galactose IgE } \\
\text { Previous reports (JACI 2009;123:426-433) have } \\
\text { demonstrated that patients with IgE antibodies to } \\
\text { galactose-a-1,3-galactose are at risk for delayed } \\
\text { anaphylaxis, angioedema, or urticaria following } \\
\text { consumption of beef, pork, or lamb. }\end{array}$ & $>100.00$ & $<0.35 \mathrm{kU} / \mathrm{L}$ \\
\hline Beef IgE & 20.1 & $<0.35 \mathrm{kU} / \mathrm{L}$ \\
\hline $\begin{array}{c}\text { Pork IgE } \\
\text { The test method is the Phadia ImmunoCAP } \\
\text { allergen-specific IgE system. } \\
\text { CLASS INTERPRETATION } \\
<0.10 \mathrm{kU} / \mathrm{L}=0 \text {, Negative; } \\
0.10-0.34 \mathrm{kU} / \mathrm{L}=0 / 1, \text { Equivocal/Borderline; } \\
0.35-0.69 \mathrm{kU} / \mathrm{L}=1 \text {, Low Positive; } \\
0.70-3.49 \mathrm{kU} / \mathrm{L}=2 \text {, Moderate Positive; } \\
3.50-17.49 \mathrm{kU} / \mathrm{L}=3 \text {, High Positive; } \\
17.50-49.99 \mathrm{kU} / \mathrm{L}=4 \text {, Very High Positive; } \\
50.00-99.99 \mathrm{kU} / \mathrm{L}=5 \text {, Very High Positive; } \\
>99.99 \mathrm{kU} / \mathrm{L}=6 \text {, Very High Positive } \\
\text { *This test was developed and its performance } \\
\text { characteristics determined by Viracor Eurofins. } \\
\text { It has not been cleared or approved by the U.S. } \\
\text { Food and Drug Administration. }\end{array}$ & 6.48 & $<0.35 \mathrm{kU} / \mathrm{L}$ \\
\hline Lamb / Mutton IGE & 14.9 & $<0.35 \mathrm{kU} / \mathrm{L}$ \\
\hline
\end{tabular}

Table 1: Component Results. 
http://www.tridhascholars.org | January-2020

Additionally, he experienced a previous episode similar to this presentation but with less severity earlier this year. His PCP attributed it to his lisinopril at the time. Within 24 hours of admission, his symptoms completely resolved with no additional interventions and were later discharged home with epinephrine-pens, diphenhydramine, instructions to follow up with his primary care physician. After discharge, his $\alpha$-gal laboratory panel returned (Table 1) and he was referred to an Allergist.

\section{Discussion}

Establishing the etiology of recurrent anaphylaxis is one of the primary goals of management to avoid repetitive exposure. In studies in which anaphylaxis had been established, foods or venom had caused the most severe reactions. Classically, IgEmediated reactions are thought to occur within five to 30 minutes after ingestion or injection of an offending allergen. However, it can, at times, occur up to two hours later. Numerous epitopes that are responsible for IgE mediated food allergy had been described and are mainly protein based. It is well known that carbohydrate moieties on many plant foods can induce anti-glycan IgE responses. However, the significance of these cross-reactive carbohydrate determinants is unclear. In contrast, recent studies have shown IgE antibodies specific for carbohydrate galactose- $\alpha$-1,3-galactose (alphagal) are capable of prompting serious and fatal reactions. Alpha-gal is produced by the alpha-1,3-galactosyltransferase enzyme, and this naturally occurring IgG to alpha-gal is responsible for mediating the hyper-acute rejection of pig-to-primate via xenotransplantation [4].

Because alpha-gal is known to be present on non-primate mammal tissues (i.e. thyroglobulin15), it was investigated if $\operatorname{IgE}$ antibodies to alpha-gal were present in the sera of adult patients reporting reactions to beef. Further screening of sera from patients in a study led to the identification of patients with a positive titer of these antibodies whose primary symptoms were recurrent episodes of anaphylaxis, angioedema, or urticaria. The characteristics of red meat allergy were different from other allergic reactions. The most common complaints included both gastrointestinal symptoms and urticaria. It was also noted that many patients with red meat allergy did not develop symptoms for at least 3-5 hours or even longer.

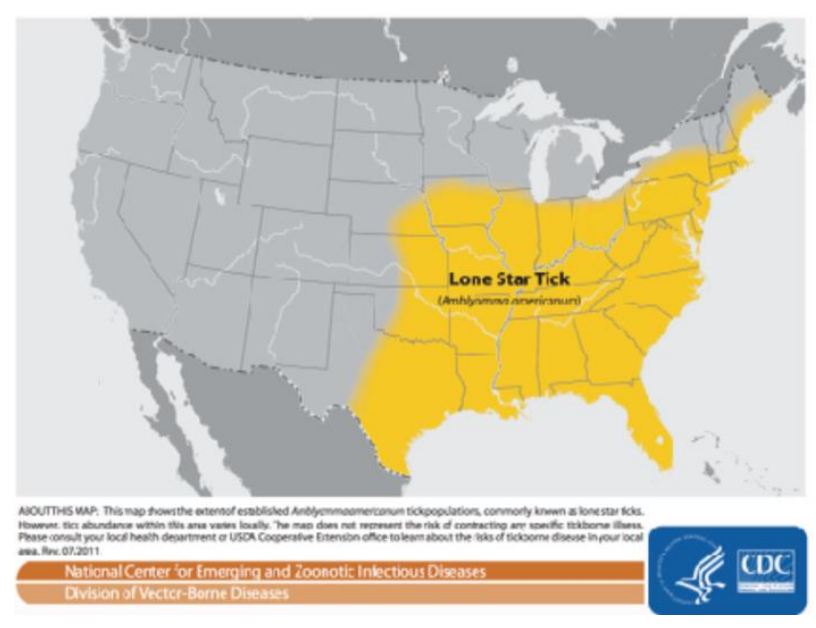

Figure 1: Lone Star tick demographical region (South Eastern United States).

Additional studies that involved the incident of both red meat allergies and cetuximab sensitivities identified a geographical commonality to an area with the maximum incidence of Rocky Mountain Spotted Fever (RMSF). Patients in this geographical area had serum collected before and after a tick bite. This demonstrated a 4 to 10 -fold increase in IgE to alpha-gal after the tick exposure. The CDC map of the tick Amblyomma americanum (Lone Star Tick) illustrates an overlapping area including both the sensitivities for red meat and cetuximab. Unlike other countries, in the United States, other tick species such as Ixodes 
scapularis have not produced similar IgE responses to alpha-gal. Australia's Ixodes holocyclus and Europe's Ixodes ricinus have both shown similar increases in IgE to $\alpha$-gal.

Recent studies suggest that patients may report a history of chigger bites, and no history of a tick bite, responsible for alpha gal sensitization.

\section{Conclusion}

Since the discovery of IgE antibodies to alpha-gal, the rules to anaphylaxis have changed and the provider should re-consider their line of questions typically asked to our patients on initial anaphylaxis presentation. We know now red meat allergies tend to have a delayed reaction of up to 3 - 5 hours and symptoms can vary from pruritus to anaphylaxis and possibly result in death. We also know, red meat should be considered as a possible anaphylotoxin in the patient population who reside in the Lone Star tick demographical region (Southeastern United States) (Figure 1).

\section{References}

1. Clark S, Camargo CA (2007) Epidemiology of anaphylaxis. Immunology and Allergy Clinics of North America 27(2): $145-63, \mathrm{v}$.

2. Commins SP, Satinover SM, Hosen J, et al. (2009) Delayed anaphylaxis, angioedema, or urticaria after consumption of red meat in patients with IgE antibodies specific for galactose- $\alpha-1$, 3-galactose. Journal of Allergy and Clinical Immunology 123(2): 426-433.

3. Steinke JW, Platts-Mills TA, Commins SP (2015) The alpha-gal story: lessons learned from connecting the dots. Journal of Allergy and Clinical Immunology 135(3): 589-596.

4. Wood RA, Camargo Jr CA, Lieberman P, et al. (2014) Anaphylaxis in America: the prevalence and characteristics of anaphylaxis in the United States. Journal of Allergy and Clinical Immunology 133(2): 461-467. 